\title{
An Evaluation of the Effectiveness of Hyaluronidase in the Selective Nerve Root Block of Radiculopathy: A Double Blind, Controlled Clinical Trial
}

\author{
Sang-Bong $\mathrm{Ko}^{1}$, Alexander R Vaccaro ${ }^{2}$, Ho-Jin Chang ${ }^{1}$, Dong-Young Shin ${ }^{1}$ \\ ${ }^{1}$ Department of Orthopaedic Surgery, Daegu Catholic University Medical College, Daegu, Korea \\ ${ }^{2}$ Department of Orthopaedic Surgery, Thomas Jefferson University, Philadelphia, PA, USA
}

Study Design: Prospective, double-blind, randomized controlled trial.

Purpose: To determine the ability of hyaluronidase to provide longer lasting pain relief and functional improvement in patients with lumbar radiculopathy.

Overview of Literature: Selective nerve root block (SNRB) is a good treatment option in lumbar radiculopathy. We studied the effectiveness of hyaluronidase when added to the traditional SNRB regimen.

Methods: A sample size of 126 patients per group was necessary. A sample of 252 patients who underwent an injection procedure with or without hyaluronidase due to radiculopathy was included in this study. The patients were randomly divided into two groups: the control (C) group and the hyaluronidase (H) group. After SNRB due to radiculopathy, the visual analog scale (VAS) was compared at 2, 4, 6, 8, and 12 weeks between the two groups, and the Oswestry disability index (ODI) was compared at 12 weeks between the two groups.

Results: Both groups seemed to have general improvement in VAS, but in $\mathrm{C}$ group, the VAS was higher than the $\mathrm{H}$ group 2 and 4 weeks after the surgery, and the difference in time-group change between 2 groups was statistically significant $(p<0.05)$. ODI improved in both groups, and the difference in time-group change between 2 groups was not statistically significant $(p>0.05)$.

Conclusions: The rebound pain (the re-occurrence of pain within 2-4 weeks after injection) that occurs within 2-4 weeks after the injection of the routine regimen can be reduced when hyaluronidase is added to the routine SNRB regimen.

Keywords: Nerve block; Hyaluronidase; Visual analog scale

\section{Introduction}

Minimally invasive procedures have gained popularity due to their potential of providing symptomatic relief while minimizing side effects and complications. In the treatment of spine pathology, epidurals and selective nerve root injections of corticosteroid are considered to be minimally invasive and are commonly used for diagnostic and therapeutic purposes. Selective nerve root block (SNRB) is a procedure used to relieve pain by plac-

Received Apr 4, 2014; Revised Sep 11, 2014; Accepted Sep 18, 2014

Corresponding author: Ho-Jin Chang

Department of Orthopaedic Surgery, Daegu Catholic University Medical College,

33 Duryugongwon-ro 17-gil, Nam-gu, Daegu 705-718, Korea

Tel: +82-53-650-4283, Fax: +82-53-626-4272, E-mail: Hoji13@cu.ac.kr 
Table 1. The inclusion and exclusion criteria

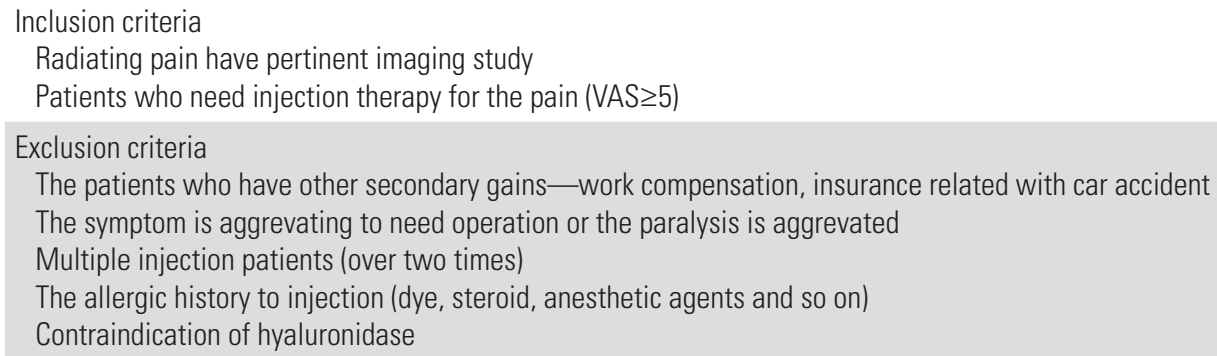

VAS, visual analog scale.

ing the corticosteroid and anesthetic agents directly into the compressed nerve, causing radiculopathy. The efficacy of SNRB as a definitive treatment option is controversial, but many authors have stated that SNRB is an effective treatment option for lumbar radiculopathy [1,2].

SNRBs include both the corticosteroid that inhibits the synthesis and release of inflammatory precursor materials and the anesthetic agents that inhibit the transmission of nociceptive signals. However, the details of the general mechanism by which SNRB provides relief remain unclear [3]. The duration of symptom relief is variable, but it is often too short for these interventions to provide effective treatment. Pfirmann et al. [4] concluded that the early response to the procedure does not predict its effect two weeks later.

In spite of the rare potential risks of injecting hyaluronidase into spinal vessels or the intra-thecal space, it is commonly and safely used as joint space substitute in the clinical field where it reduce swelling, fibrosis, and edema from trauma [5].

The purpose of this study was to determine the ability of hyaluronidase to provide longer lasting pain relief as well as its ability to reduce rebound pain.

\section{Materials and Methods}

\section{Design}

After obtaining informed, written consent, the patients were enrolled in the study, which was approved by the Institutional Review Board. A double-blinded, prospective, randomized, and controlled clinical trial was conducted comparing SNRBs with and without hyaluronidase. This trial was set up as a parallel group study and used equal randomization, 1:1, for the two groups. With a two-sided $5 \%$ significance level and a power of $80 \%$, a sample size of 126 patients per group was necessary, given the anticipated dropout rate of $10 \%$.

\section{Subjects}

Patients who were evaluated at the Orthopedic Department of our hospital, between March 2004 and March 2012 with radicular pain in the presence of radiographically confirmed lumbar spinal stenosis and lumbar disk herniation were recruited for the study. Native and postoperative radiculopathies were included in this study as well. If the radicular pain was bilateral, the side with more severe pain was selected, and the injection was given regardless of the symptom durations. All of the patients were informed of the analgesic, which is not an opioid, before the injection, and the injection therapy was received for the first time in all of the patients. The imaging findings were diagnosed and confirmed by two radiologists and two orthopedic surgeons. The procedures were explained to all patients, and written consent was received from the patients. The patients and surgeons did not know to which group each patient belonged. The inclusion and exclusion criteria are shown in Table 1.

\section{Methods}

1) Patient selection

Fig. 1 shows overall trial design and patient participation. A total of 252 patients were randomly divided into two groups, the control $(\mathrm{C})$ and hyaluronidase $(\mathrm{H})$ groups, by a blinded senior resident and circulating nurse with no other involvement in this study. The sequence was generated by the process of minimization. The details of the series were unknown to any of the investigators. Even after injection, the investigators had no knowledge of which patient was in group $\mathrm{C}$ or group $\mathrm{H}$. After finishing the 


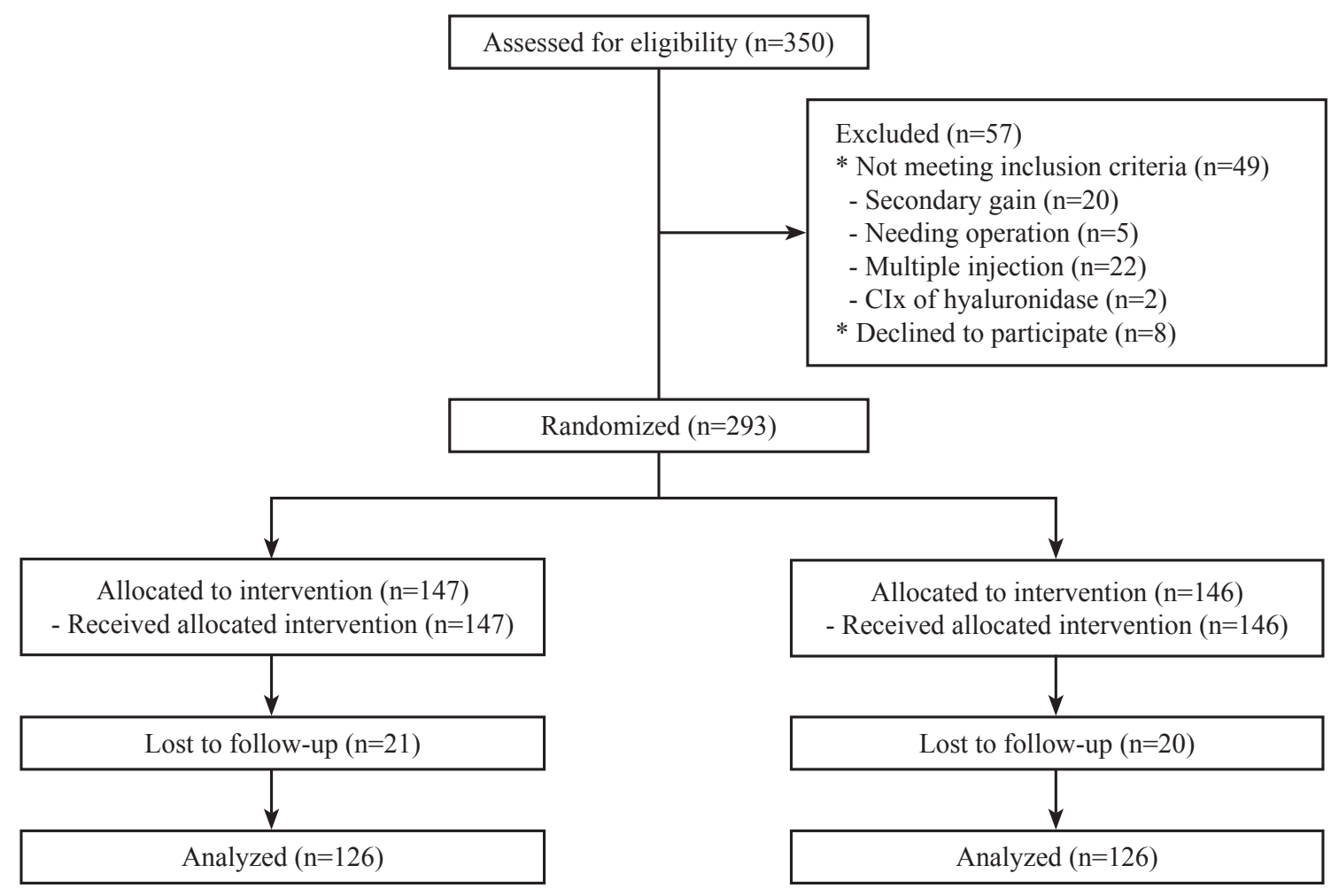

Fig. 1. Flow diagram showing the procedure used in the study.

last evaluation, the blinded researcher obtained the outcome and the group assignments, and then he analyzed the data.

Group C received triamcinolone $1 \mathrm{~mL}(40 \mathrm{mg} / \mathrm{mL}$, Triam injection, Dong-kwang Pharm Co., Seoul, Korea), $025 \%$ bupivacaine $1 \mathrm{~mL}$, and normal saline $1 \mathrm{~mL}$ and group $\mathrm{H}$ received triamcinolone $1 \mathrm{~mL}, 0.25 \%$ bupivacaine $1 \mathrm{~mL}$, normal saline $1 \mathrm{~mL}$ and hyaluronidase 1,500 IU. The medications were mixed by the circulating nurse and the contents of the injection were not shared with the patient or the physician performing the SNRB. Care was taken to ensure all of the injections were performed in as much of an identical manner as possible. The two groups were followed to determine the degree and the duration of pain relief. The patients were recommended not to use analgesics, physical therapy, or any other pain relieving interventions for at least three months following their SNRB. If the pain worsened during the follow-up period and intervention was required, an oral steroid (triamcinolone $2 \mathrm{mg}$ ) was prescribed. Failure in treatment was defined as continuous pain requiring intervention or to the extent the patient had to request additional injections or surgery.
2) The procedure

All SNRBs were performed as outpatient procedures without premedication. The patient was set in the prone position on an X-ray table and the injection site was prepped and draped in the standard sterile manner. The puncture point was determined by obtaining an oblique fluoroscopic view of a specific spinal nerve root such that the apex of the superior articular process of the ipsisegmental zygapophyseal joint pointed directly upward towards the target pedicle. The skin was injected with $2 \%$ lidocaine and a 23 -gauge spinal needle was used for the SNRB after fluoroscopic localization. Under repeated fluoroscopic screening, the needle was advanced slowly towards the base of the pedicle until could not be advanced farther due to bony contact. The objective was to reproduce the patient's pain by striking the nerve. Concordance between the evoked pain and the patient's accustomed pain was taken as the cardinal indication. Once the needle was in the correct position, the contrast medium (Iohexol, Omnipaque GE Healthcare Ireland, Cork, Ireland; $300 \mathrm{mg} / \mathrm{mL}$ ) injection was made to verify the correct placement of the needle. Approximately 0.8 $\mathrm{mL}$ of the contrast medium was injected slowly under a direct visualization to indicate the direction and extent 
Table 2. General epidemiological characteristics of patients

\begin{tabular}{|c|c|c|c|}
\hline \multirow{2}{*}{ Variable } & \multicolumn{2}{|c|}{ Group } & \multirow{2}{*}{$\chi^{2} \mathrm{t}$ or ( $p$-value) } \\
\hline & C & $\mathrm{H}$ & \\
\hline Age & 61.299 (15.841) & $62.286(13.271)$ & $-0.537^{\mathrm{a})}(0.592)$ \\
\hline Body weight (kg) & $60.78(10.2)$ & $61.984(11.29)$ & $-0.891^{\mathrm{a})}(0.374)$ \\
\hline Height $(\mathrm{cm})$ & 163.559 (53.028) & $162.837(8.154)$ & $0.151^{\text {a) }}(0.880)$ \\
\hline Sex & & & $0.002^{b)}(0.965)$ \\
\hline Female & $84(67.7)$ & $85(67.5)$ & \\
\hline Male & 41 (32.3) & 41 (32.5) & \\
\hline
\end{tabular}

Values are presented as mean \pm standard deviation or number (\%).

$\mathrm{H}$ group, regimen consist of triamcinolone $1 \mathrm{~mL}+0.5 \%$ bupivacaine $1 \mathrm{~mL}$ +hyaluronidase 1,500 IU+normal saline $1 \mathrm{~mL}$; $\mathrm{C}$ group, regimen consist of triamcinolone $1 \mathrm{~mL}+0.5 \%$ bupivacaine $1 \mathrm{~mL}+$ normal saline $1 \mathrm{~mL}$.

${ }^{a}$ Result of two sample $t$-test; ${ }^{\text {bl }}$ Result of chi-square test.

of spreading of the solutions that will subsequently be injected. Once an appropriate dispersal of contrast medium was established, the syringe containing the contrast medium was replaced with one containing the appropriate medication (group $\mathrm{C}$ vs. group $\mathrm{H}$ ).

\section{3) Evaluation}

The treating spine surgeon was blinded to the medication throughout the entire period of the study. Preoperative evaluation included the visual analogue scale (VAS) for pain and the Oswestry disability index (ODI) for function, and it was supervised by a senior resident in the waiting room before the injection procedure. Followup evaluation included documentation of the VAS and examination for any complications at 2, 4, 6, 8, and 12 weeks. Post-injection ODI was obtained at 12 weeks after the procedure. We used an analysis of repeated measure two-factor analysis. The SPSS ver. 14.0 (SPSS Inc., Chicago, IL, USA) statistics program for Windows was used for all analysis. A $p$-value of less than or equal to 0.05 was
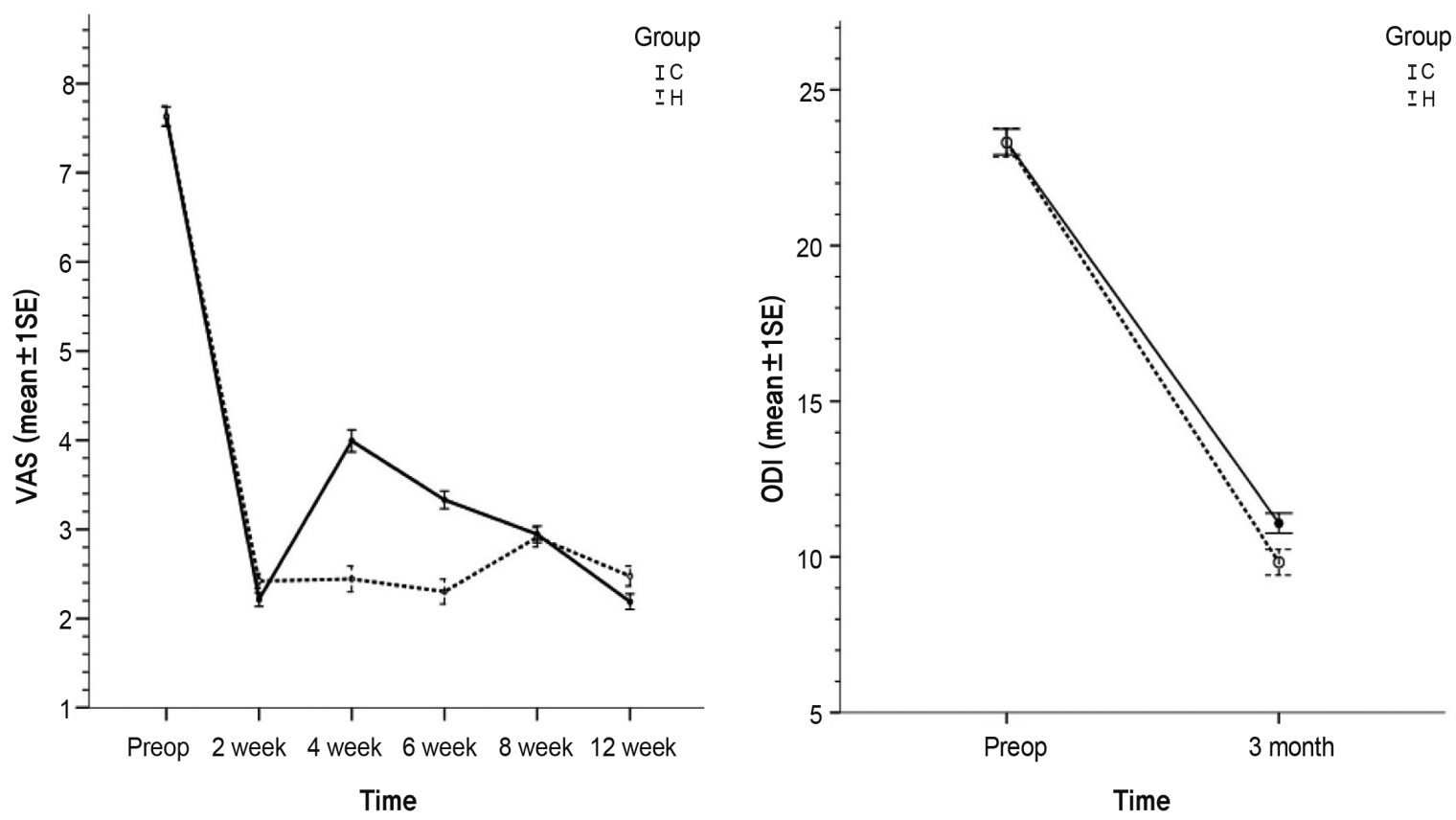

Fig. 2. Plots for VAS and ODI variables by time and group. Preop, preoperative; $\mathrm{C}$, control; $H$, hyaluronidase; VAS, visual analog scale; ODI, Oswestry disability index; SE, standard error. 


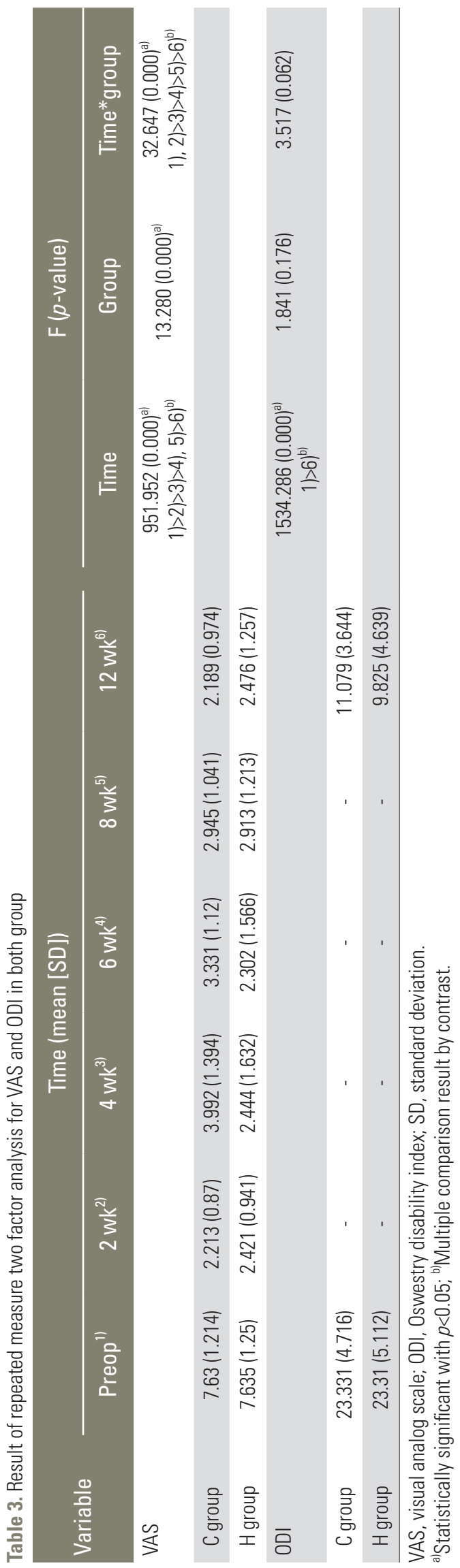

considered to be statistically significant.

\section{Results}

A total of 252 patients completed the procedure and the 12 weeks of follow-up included 126 patients in each group. There was no significant difference in age, gender ratio, body weight or height between the two groups (all p-values $>0.05$ ) (Table 2).

Fig. 2 is the graph showing the change of VAS and ODI at each period in the two groups. In group H, VAS decreased from 2 weeks and was maintained thereafter, and in group C, VAS decreased at 2 weeks, then increased over weeks $2-4$, and then decreased thereafter. The change of time-group in each group had statistical significance ( $p=0.000$ ) (Table 3 ). In terms of ODI, there was a significant reduction at week 12 after the injection in both groups (Fig. 2). The difference between the groups for time-group was not statistically significant $(p=0.062)$ (Table 3).

\section{Discussion}

SNRBs can be used for both diagnostic and therapeutic purposes. Diagnostically, they can determine which amount of patient's pain is due to the individual's spinal root [6-10]. Furthermore, many authors have reported that SNRB can provide symptomatic relief for patients who have acute or chronic low back pain associated with leg radiculopathy [2,11-15]. Goebert et al. [16] reported that one cause of low back pain and radiculopathy is inflammation around the nerve root. This supports the idea that a targeted steroid and procaine around the nerve root may be an effective treatment for the low back pain and radiculopathy.

The anti-inflammatory properties of corticosteroid are also well known [17]. Their local application is considered to relieve reversible inflammatory changes or processes, such as vascular congestion related to mechanical obstruction $[17,18]$. It has been shown that most disc herniation gradually resorbs on its own [19]. Therefore, in the treatment of patients with intractable radicular pain, the use of therapeutic SNRB to deliver corticosteroids locally appears to be rational [2]. The objective of the therapeutic SNRB is not to "cure" the patient by interfering with the pathogenetic factors responsible for the sciatica, but rather to provide temporary relief from peak 
pain during the time required for the spontaneous resolution of the radiculopathy [4].

In the well-selected patients, SNRB routinely provides near-complete pain relief for at least 2-3 days. Symptom recurrence was experienced by approximately $35 \%$ of the patients within 2 weeks. Some authors have reported that the mean time to symptom recurrence was approximately 2 months after injection, and no recurrences occurred after 9 or more months of relief. Both Ridley et al. [20] and Carette et al. [21] stated that SNRB in patients with herniated intervertebral discs were effective after two weeks, but did not have a lasting effect. McLain et al. [22] reported that transforaminal epidural steroid injections showed long-term pain relief in only $25 \%-57 \%$ of the subjects and in $50 \%-75 \%$ of subjects who showed temporary relief of their symptoms. Similarly, Buttermann [23] stated that $45 \%-50 \%$ of the patients' pain recurred at 3 months after epidural injections. One potential reason for the limited duration of the steroids' effect is that steroids do not significantly affect the processes occurring in the latter stages of inflammations such fibrocyte proliferation, collagen deposition, and cicatrization around the nerve roots [24]. In this study, the pain also recurred during the two to four week period after injection.

Hyaluronidase is a water-soluble enzyme prepared from mammalian testes or intestines. It has been used extensively in various clinical fields to render tissues more permeable to fluids such as hypodermoclysis, local anesthetics, or radio-opaque dyes. It has been shown to improve absorption of pleural, peritoneal, or joint effusions and to reduce swelling, fibrosis, and edema from trauma [5]. The mechanism action postulated for the therapeutic efficacy of hyaluronidase is the hydrolysis of the glycosaminic bonds of hyaluronic acid and other mucopolysaccharides of the connective tissue. This may be particularly important for patients with fibrous tissue deposition around injured nerve roots, which causes ongoing compression, limited mobility of the nerves, and restricted blood circulation $[25,26]$. This scar tissue can also limit the diffusion of drugs, thereby limiting the efficacy of the injection [27].

Hyaluronidase is a drug that has been tested to be capable of overcoming the limited duration and effects of steroid injections [28]. Kim et al. [28] found an additional effect of hyaluronidase in lumbar epidural injections for patients with pain attributable to a disc herniation. They reported an extension in the duration of pain relief and improvement in short term subjective functional outcomes.

This study was limited by the small sample size and limited duration of the follow-ups. However, it serves as an important result showing the therapeutic effect of this enzyme through spinal injection. Further studies are needed to determine the optimal patient population, dosage, and long term efficacy, as well as to obtain more information on potential side effects.

\section{Conclusions}

The rebound pain that occurred 2-4 weeks after the routine SNRB regimen (triamcinolone, lidocaine, bupivacaine cocktail) could be significantly reduced by adding hyaluronidase to the regimen. However, there was no significant change, despite the addition of hyaluronidase, on pain or ODI 3 months after the injection.

\section{Conflict of Interest}

No potential conflict of interest relevant to this article was reported.

\section{References}

1. Riew KD, Park JB, Cho YS, et al. Nerve root blocks in the treatment of lumbar radicular pain. A minimum five-year follow-up. J Bone Joint Surg Am 2006;88: 1722-5.

2. Riew KD, Yin Y, Gilula L, et al. The effect of nerveroot injections on the need for operative treatment of lumbar radicular pain. A prospective, randomized, controlled, double-blind study. J Bone Joint Surg Am 2000;82:1589-93.

3. Abdi S, Datta S, Trescot AM, et al. Epidural steroids in the management of chronic spinal pain: a systematic review. Pain Physician 2007;10:185-212.

4. Pfirrmann CW, Oberholzer PA, Zanetti M, et al. Selective nerve root blocks for the treatment of sciatica: evaluation of injection site and effectiveness: a study with patients and cadavers. Radiology 2001;221:70411.

5. Borg PA, Krijnen HJ. Hyaluronidase in the management of pain due to post-laminectomy scar tissue. Pain 1994;58:273-6.

6. Dooley JF, McBroom RJ, Taguchi T, Macnab I. Nerve 
root infiltration in the diagnosis of radicular pain. Spine (Phila Pa 1976) 1988;13:79-83.

7. Howe J, Frymoyer JW. The effects of questionnaire design on the determination of end results in lumbar spinal surgery. Spine (Phila Pa 1976) 1985;10:804-5.

8. Sanderson PL, Wood PL. Surgery for lumbar spinal stenosis in old people. J Bone Joint Surg Br 1993;75: 393-7.

9. Van Akkerveeken PF. Pain patterns and diagnostic blocks. In: Herkowitz H, Weinstein JN, Wiesel SW, editors. The lumbar spine. 3rd ed. Philadelphia: WB Saunders Co.; 1990. p.107-32.

10. White AH, Derby R, Wynne G. Epidural injections for the diagnosis and treatment of low-back pain. Spine (Phila Pa 1976) 1980;5:78-86.

11. Berman AT, Garbarino JL Jr, Fisher SM, Bosacco SJ. The effects of epidural injection of local anesthetics and corticosteroids on patients with lumbosciatic pain. Clin Orthop Relat Res 1984;(188):144-51.

12. Brown FW. Management of diskogenic pain using epidural and intrathecal steroids. Clin Orthop Relat Res 1977;(129):72-8.

13. Crock HV. Normal and pathological anatomy of the lumbar spinal nerve root canals. J Bone Joint Surg Br 1981;63:487-90.

14. Haueisen DC, Smith BS, Myers SR, Pryce ML. The diagnostic accuracy of spinal nerve injection studies. Their role in the evaluation of recurrent sciatica. Clin Orthop Relat Res 1985;(198):179-83.

15. Kikuchi S, Hasue M, Nishiyama K, Ito T. Anatomic and clinical studies of radicular symptoms. Spine (Phila Pa 1976) 1984;9:23-30.

16. Goebert HW Jr, Jallo SJ, Gardner WJ, Wasmuth CE. Painful radiculopathy treated with epidural injections of procaine and hydrocortisone acetate: results in 113 patients. Anesth Analg 1961;40:130-4.

17. Olmarker K, Byrod G, Cornefjord M, Nordborg C, Rydevik B. Effects of methylprednisolone on nucleus pulposus-induced nerve root injury. Spine (Phila $\mathrm{Pa}$
1976) 1994;19:1803-8.

18. Derby R, Bogduk N, Kine G. Precision percutaneous blocking procedures for localizing spinal pain. II The lumbar neuroaxial compartment. Pain Dig 1993;3: 89-100.

19. Bozzao A, Gallucci M, Masciocchi C, Aprile I, Barile A, Passariello R. Lumbar disk herniation: MR imaging assessment of natural history in patients treated without surgery. Radiology 1992;185:135-41.

20. Ridley MG, Kingsley GH, Gibson T, Grahame R. Outpatient lumbar epidural corticosteroid injection in the management of sciatica. Br J Rheumatol 1988; 27:295-9.

21. Carette S, Leclaire R, Marcoux S, et al. Epidural corticosteroid injections for sciatica due to herniated nucleus pulposus. N Engl J Med 1997;336:1634-40.

22. McLain RF, Kapural L, Mekhail NA. Epidural steroid therapy for back and leg pain: mechanisms of action and efficacy. Spine J 2005;5:191-201.

23. Buttermann GR. Treatment of lumbar disc herniation: epidural steroid injection compared with discectomy. A prospective, randomized study. J Bone Joint Surg Am 2004;86:670-9.

24. Jo DH, Hong JH, Kim MH. The effect of transforaminal epidural block with hyaluronidase and triamcinolone. Korean J Pain 2005;18:176-80.

25. Mooij JJ. Spinal arachnoiditis: disease or coincidence? Acta Neurochir (Wien) 1980;53:151-60.

26. Pountain GD, Keegan AL, Jayson MI. Impaired fibrinolytic activity in defined chronic back pain syndromes. Spine (Phila Pa 1976) 1987;12:83-6.

27. Fredman B, Nun MB, Zohar E, et al. Epidural steroids for treating "failed back surgery syndrome": is fluoroscopy really necessary? Anesth Analg 1999;88:36772.

28. Kim SB, Lee KW, Lee JH, Kim MA, Kim BH. The additional effect of hyaluronidase in lumbar interlaminar epidural injection. Ann Rehabil Med 2011;35: 405-11. 